Supporting Information

\title{
MXene/activated carbon hybrid capacitive deionization for permselective ion removal at low and high salinity
}

\author{
Mohammad Torkamanzadeh, ${ }^{1,2}$ Lei Wang, ${ }^{1,2}$ Yuan Zhang, ${ }^{1,2}$ \\ Öznil Budak, ${ }^{1,2}$ Pattarachai Srimuk, ${ }^{1}$ Volker Presser, ${ }^{1,2, *}$
}

1 INM - Leibniz Institute for New Materials, D2 2, 66123, Saarbrücken, Germany

2 Department of Materials Science \& Engineering, Saarland University, Campus D2 2, 66123, Saarbrücken, Germany

* Corresponding author's email: presser@presser-group.com 

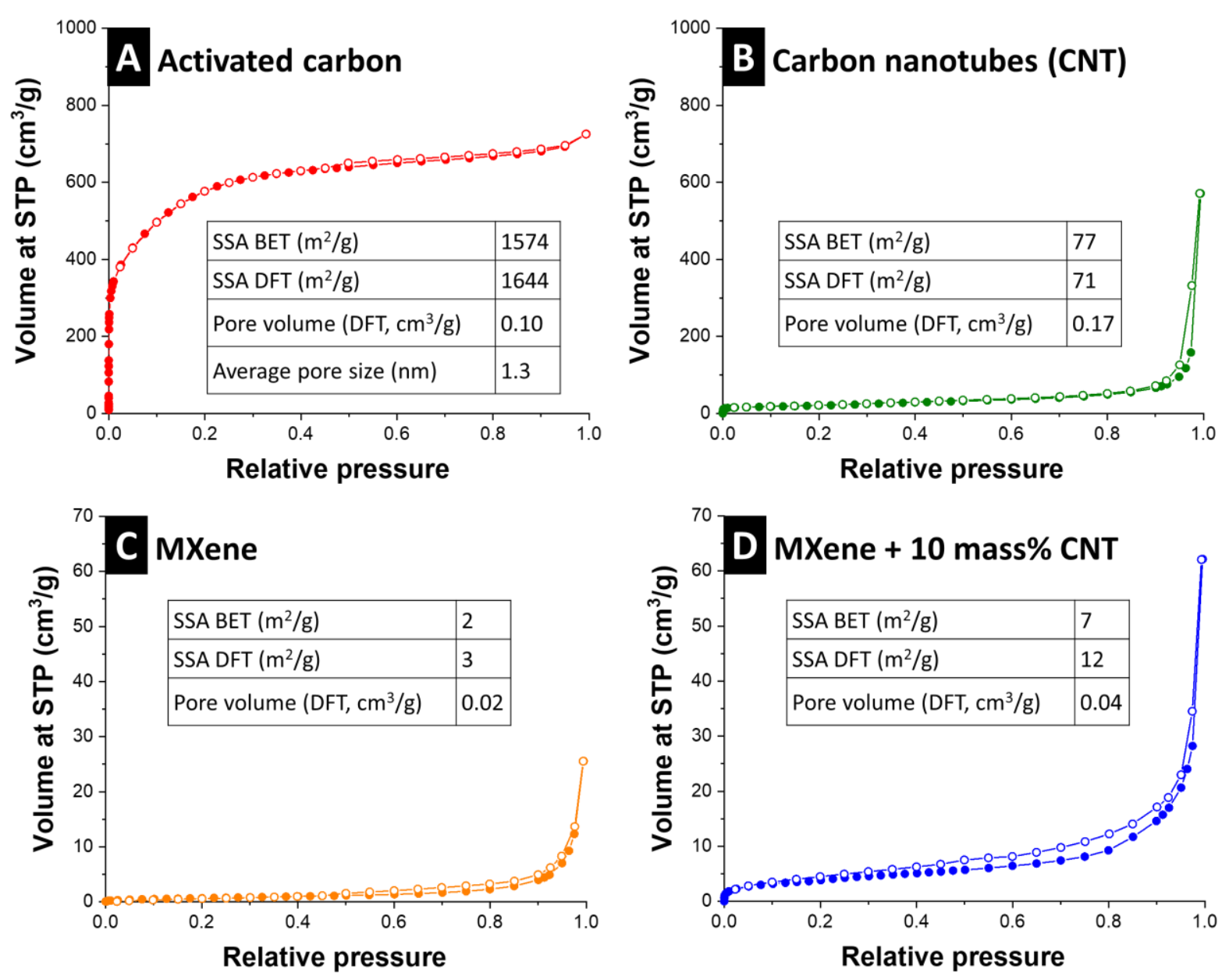

Figure S1: Nitrogen gas sorption isotherm of (A) activated carbon, (B) carbon nanotubes, (C) MXene powder, and (D) MXene/carbon nanotube electrodes recorded at a temperature of $-196^{\circ} \mathrm{C}$. STP: standard temperature and pressure.
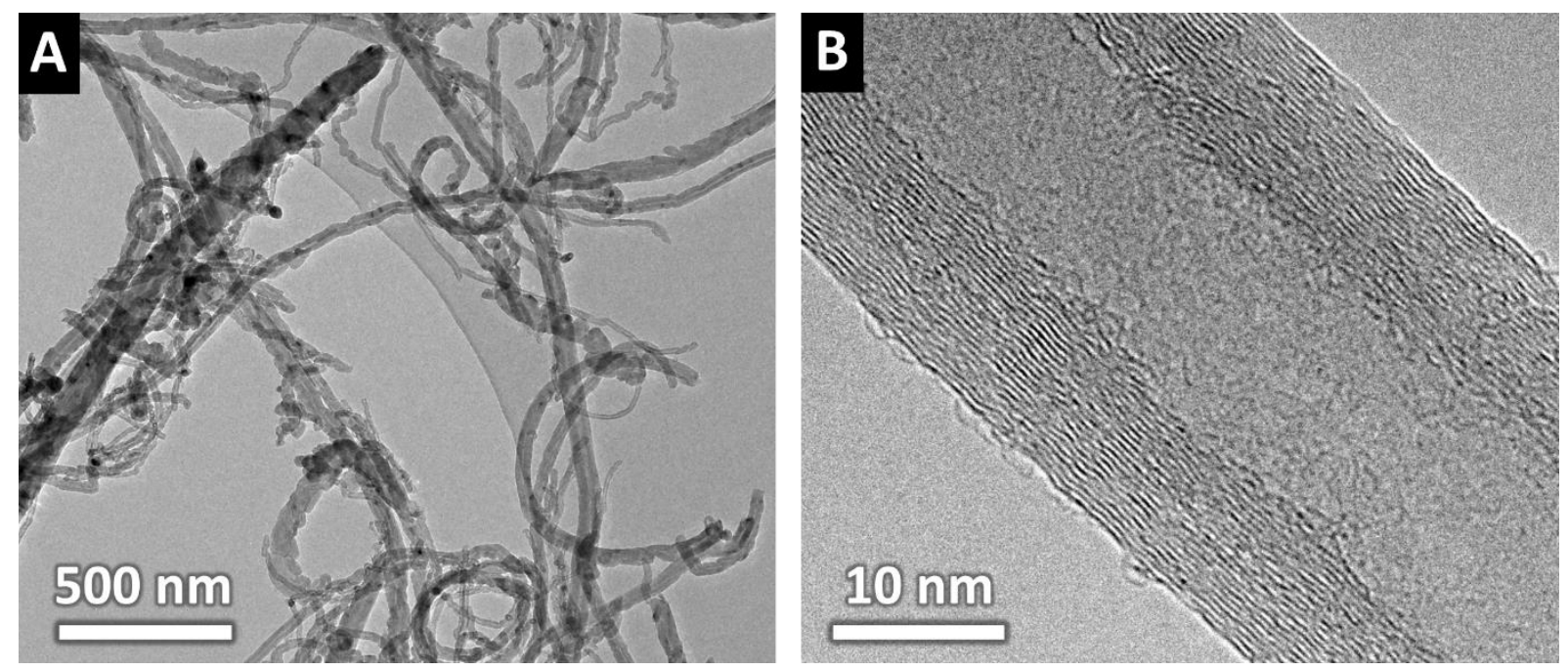

Figure S2: Transmission electron micrographs of the carbon nanotubes. 


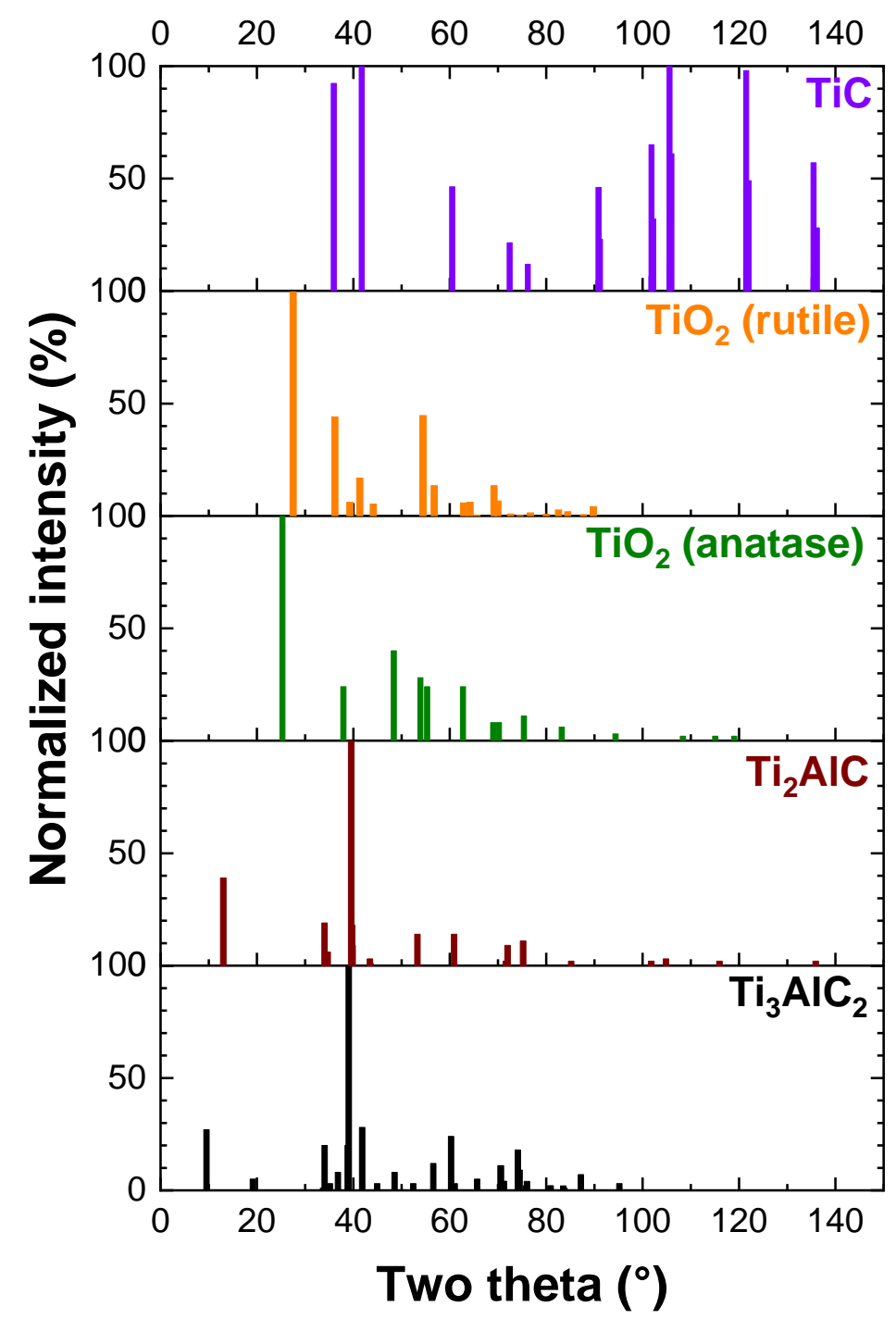

Figure S3: Relative intensities of the reference phases provided in Figure 2D. 


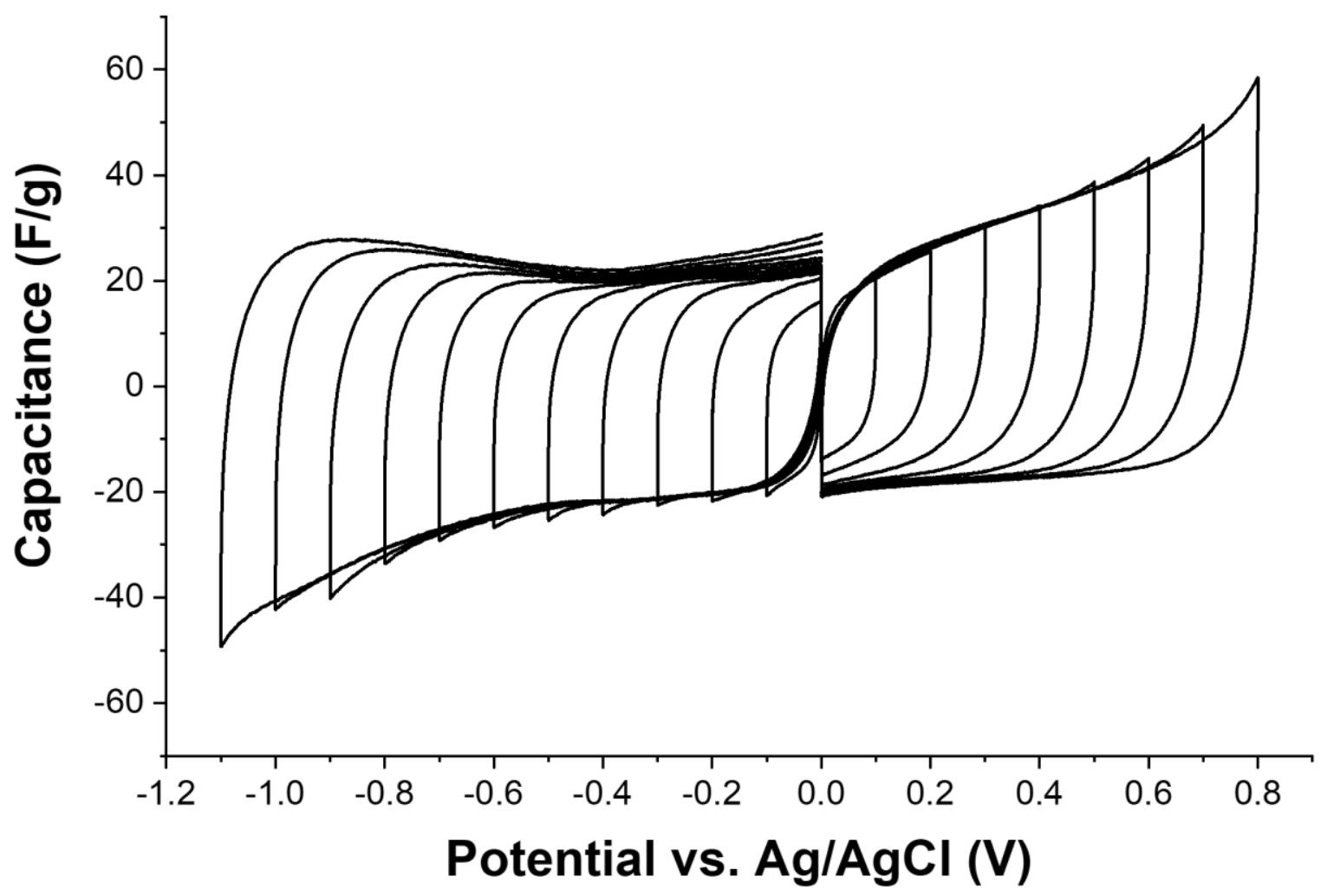

Figure S4: Half-cell window opening cyclic voltammograms of electrodes just composed of CNTs in aqueous $1 \mathrm{M} \mathrm{NaCl}$ electrolyte. 


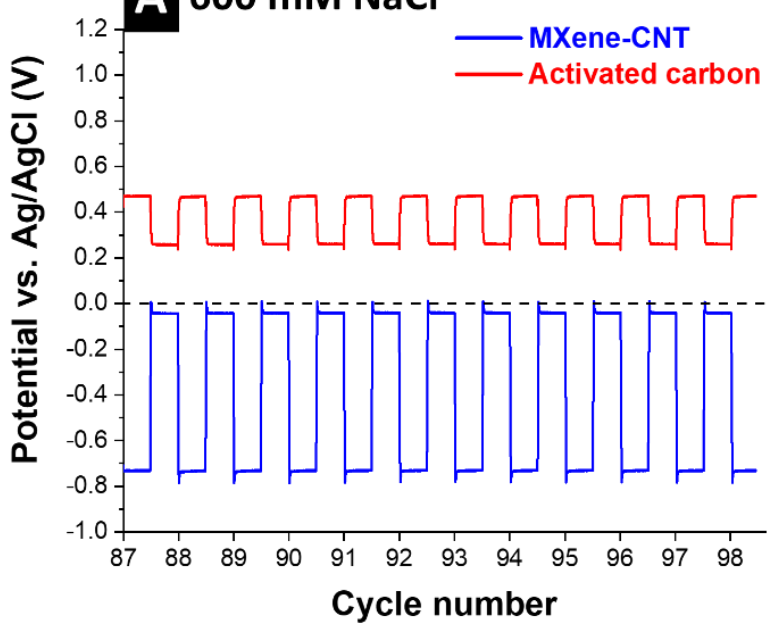

B $600 \mathrm{mM} \mathrm{NaCl}$ with AEM
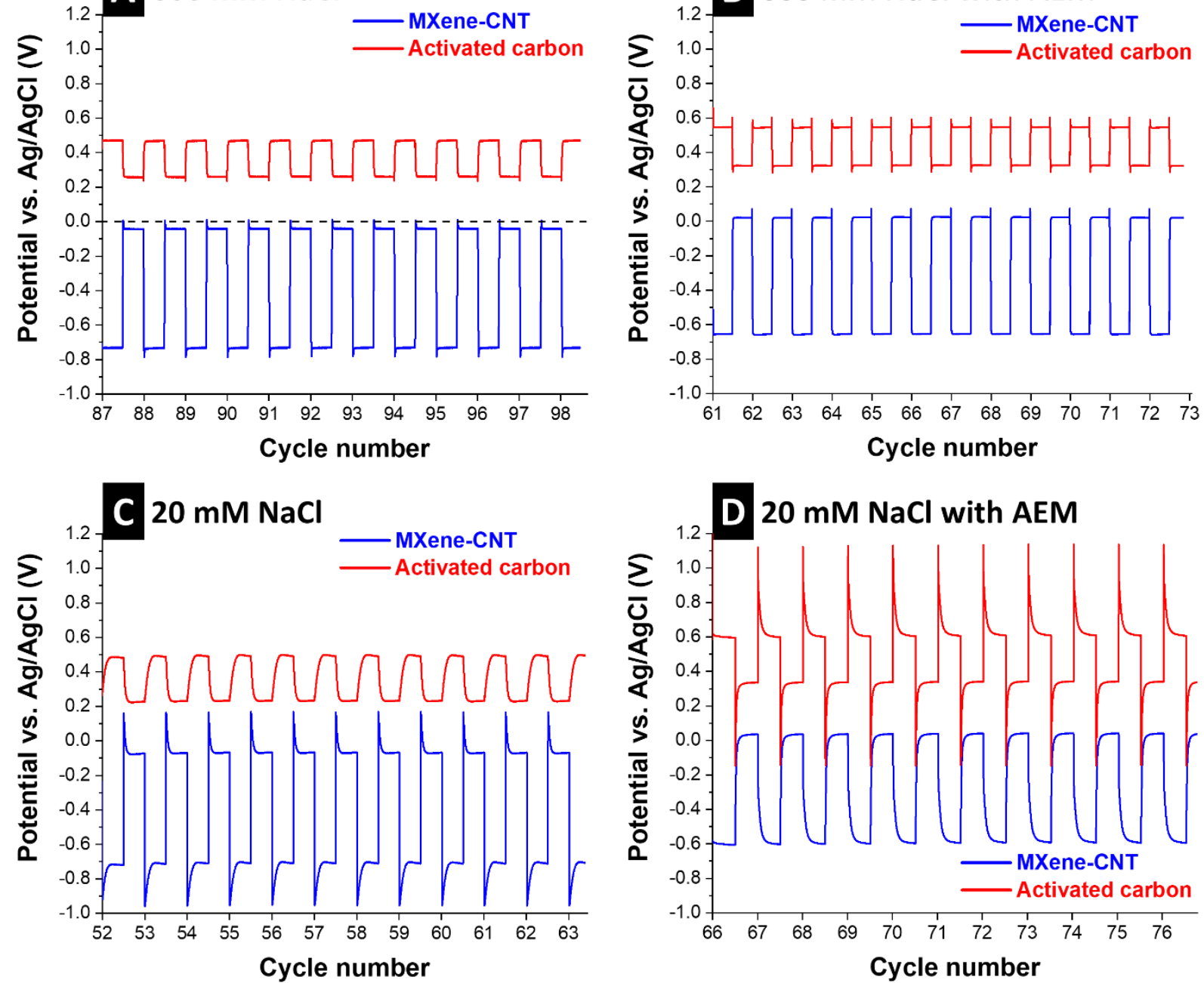

Figure S5: Potential development of individual electrodes upon charging the MXene/AC cell to a cell voltage of $1.2 \mathrm{~V}$ and discharging to a cell voltage of $0.3 \mathrm{~V}$. (A-B) aqueous $600 \mathrm{mM} \mathrm{NaCl}$; (C-D) aqueous $20 \mathrm{mM} \mathrm{NaCl}$; (A,C) without an anion-exchange membrane (AEM) placed in front of the activated carbon electrode; $(B, D)$ experiments with an AEM at the activated carbon electrode. 


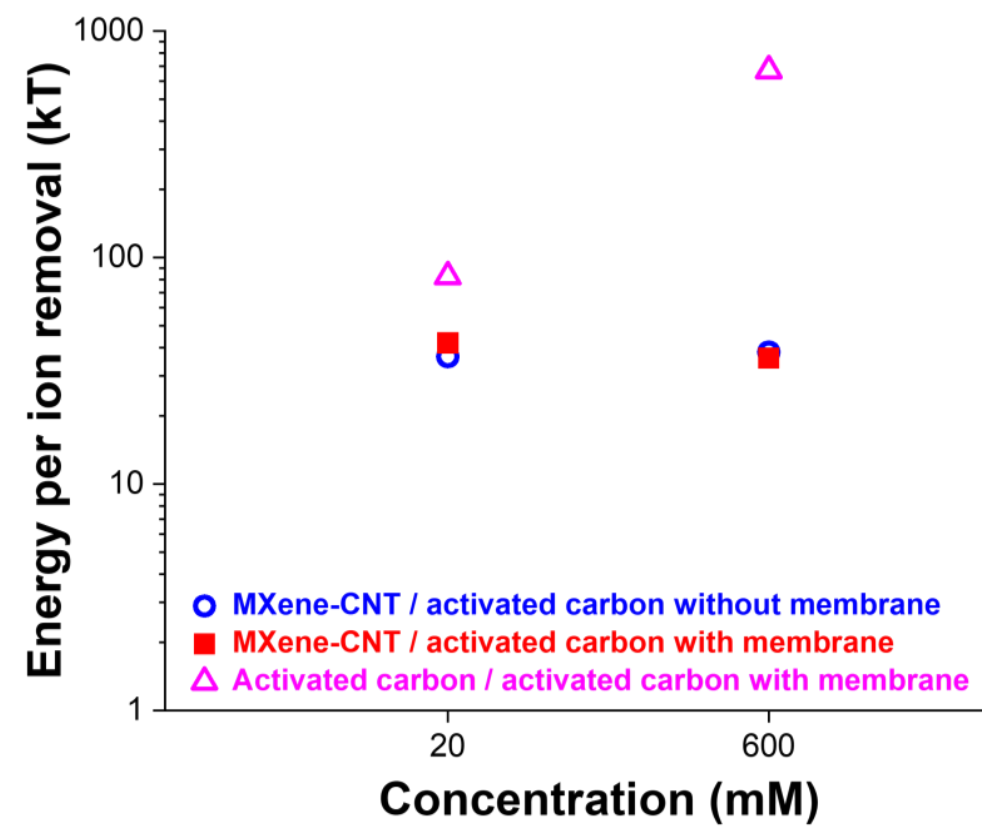

Figure S6: Energy consumption per ion removal.

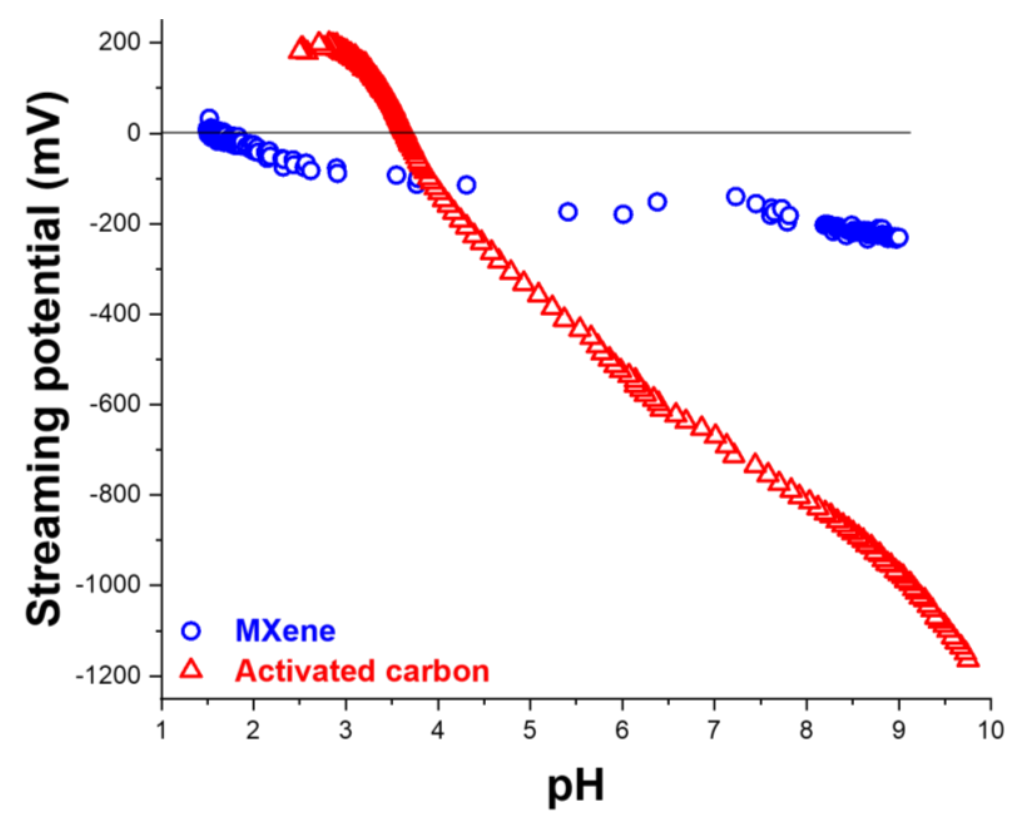

Figure S7: Streaming potential response of MXene and activated carbon in water. 

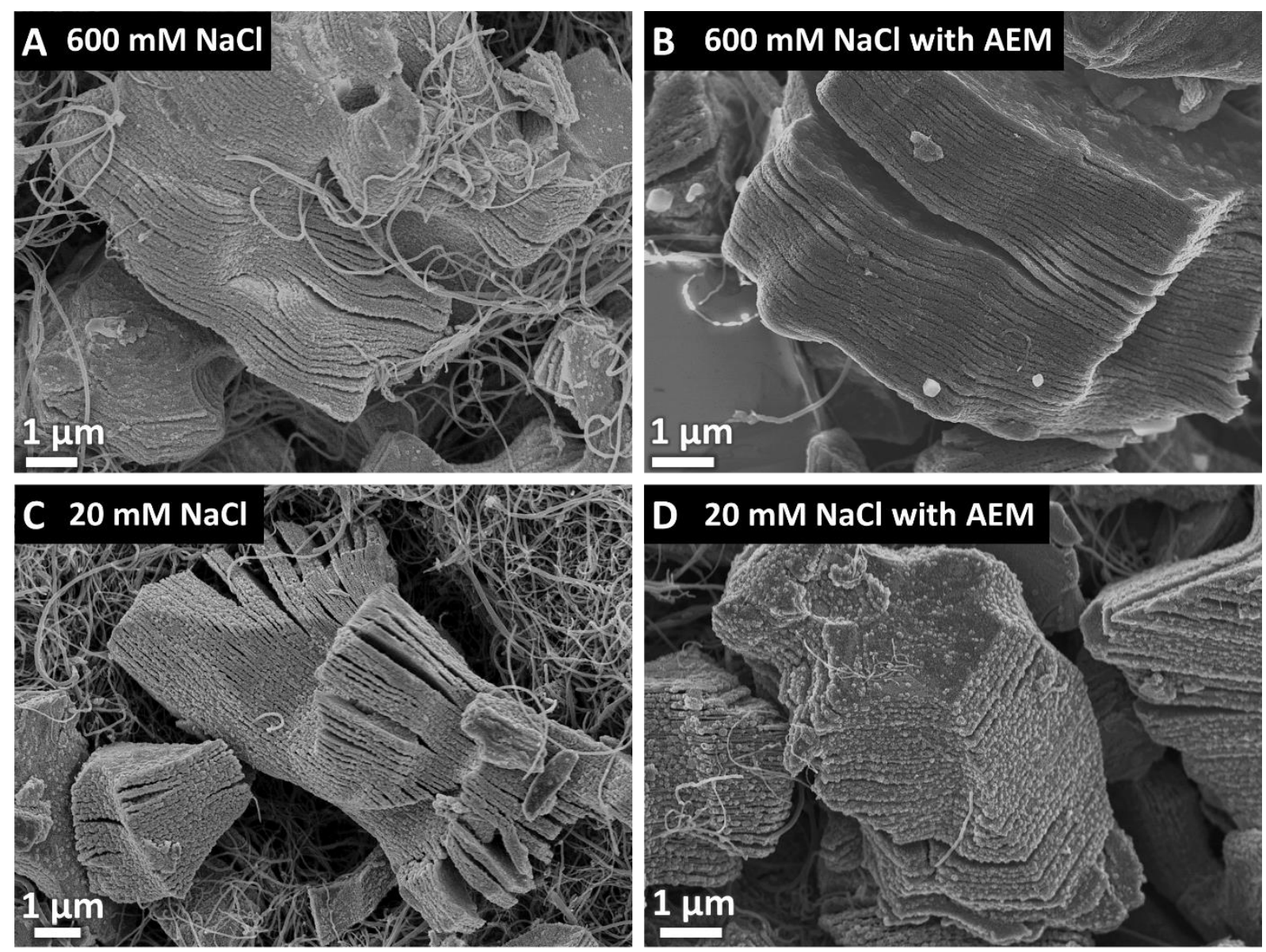

Figure S8: Post mortem scanning electron micrographs of MXene-CNT electrodes. 


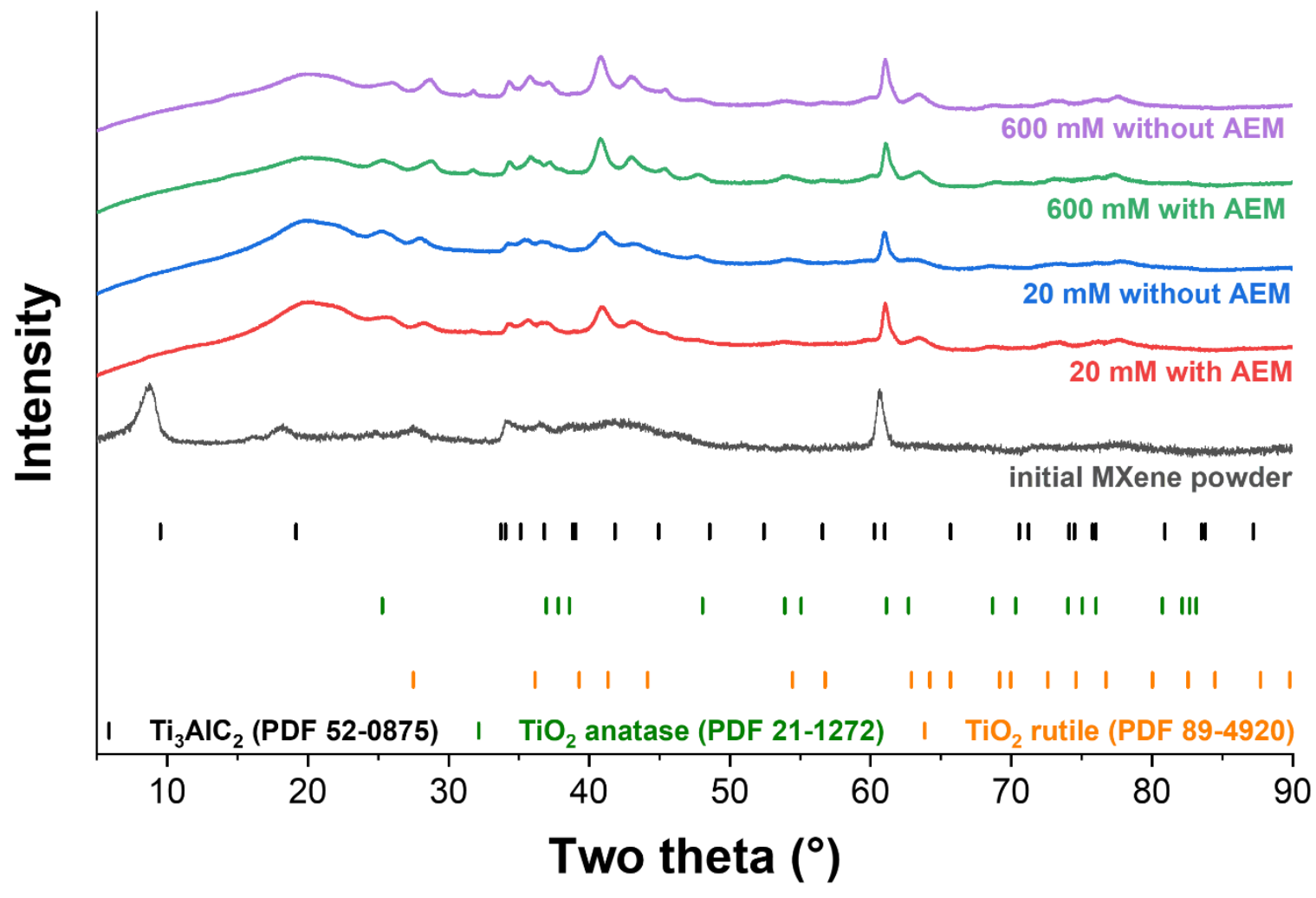

Figure S9: X-ray powder diffraction pattern of the initial MXene powder and after electrochemical operation for desalination (post mortem). 